\title{
Still a Case of "No Pain, No Gain"? An Updated and Critical Review of the Pathogenesis, Diagnosis, and Management Options for Hemorrhoids in 2020
}

\author{
Kheng-Seong $\mathrm{Ng}^{1,2}$, Melanie Holzgang ${ }^{3}$, Christopher Young ${ }^{1,2}$ \\ ${ }^{1}$ Institute of Academic Surgery, University of Sydney, Sydney; ${ }^{2}$ Department of Colorectal Surgery, Royal Prince Alfred Hospital, Sydney, \\ Australia; ${ }^{3}$ Department of Colorectal Surgery, St. James's University Hospital, Leeds, UK
}

The treatment of haemorrhoids remains challenging: multiple treatment options supported by heterogeneous evidence are available, but patients rightly demand a tailored approach. Evidence for newer surgical techniques that promise to be less painful has been conflicting. We review the current evidence for management options in patients who present with varying haemorrhoidal grades. A review of the English literature was performed utilizing MEDLINE/PubMed, Embase, and Cochrane databases (31 May 2019). The search terms (haemorrhoid OR haemorrhoid OR haemorrhoids OR haemorrhoids OR "Hemorrhoid"[Mesh]) were used. First- and second-degree haemorrhoids continue to be managed conservatively. The easily repeatable and cost-efficient rubber band ligation is the preferred method to address minor haemorrhoids; long-term outcomes following injection sclerotherapy remain poor. Conventional haemorrhoidectomies (Ferguson/Milligan-Morgan/Ligasure haemorrhoidectomy) still have their role in third- and fourth-degree haemorrhoids, being associated with lowest recurrence; nevertheless, posthaemorrhoidectomy pain is problematic. Stapled haemorrhoidopexy allows quicker recovery, albeit at the costs of higher recurrence rates and potentially serious complications. Transanal Haemorrhoidal Dearterialization has been promoted as nonexcisional and less invasive, but the recent HubBLe trial has questioned its overall place in haemorrhoid management. Novel "walk-in-walk-out" techniques such as radiofrequency ablations or laser treatments will need further evaluation to define their role in modern-day haemorrhoid management. There are numerous treatment options for haemorrhoids, each with their own evidence-base. Newer techniques promise to be less painful, but recurrence rates remain an issue. The balance continues to be sought between long-term efficacy, minimisation of postoperative pain, and preservation of anorectal function.

Keywords: Haemorrhoids; Haemorrhoidectomy; Rectal diseases; Disease management; Surgical procedure

\section{INTRODUCTION}

Haemorrhoids are among the best-described diseases in medical history, and have vexed mankind since antiquity. The oldest con-

Received: January 11, 2020 - Accepted: May 4, 2020

Correspondence to: Christopher J. Young, MBBS, MS, FRACS, FACS, FASCRS RPAH Medical Centre, Suite G07, 100 Carillon Avenue, Newtown NSW 2042, Australia

Tel: +61-2-9519-0064,E-mail: cyoungnsw@aol.com ORCID: https://orcid.org/0000-0002-7213-5137

(C) 2020 The Korean Society of Coloproctology

This is an open-access article distributed under the terms of the Creative Commons Attribution NonCommercial License (https://creativecommons.org/licenses/by-nc/4.0) which permits unrestricted noncommercial use, distribution, and reproduction in any medium, provided the original work is properly cited. vincing descriptions of haemorrhoids date back to $1500 \mathrm{BC}$ in Mesopotamia, and Biblical references to plagues of 'emerods' [arch. haemorrhoids] cement their position as a proctological condition of the ages. Ancient treatment for haemorrhoids makes for equally interesting reading, and has varied between hot iron cauterisation, leech application, and the Hippocratic suggestion of "transfixing them with a needle and tying them with a very thick and large woollen thread" [1].

While options for the surgical management of haemorrhoids have advanced since then, the choice between the various treatment modalities is not always easy. Within the last 2 decades at least, newer therapies have promised to offer less painful and less invasive treatments with quicker return of function, making the efforts of a coloproctologist to offer a tailored management strat- 
egy for each patient even more challenging, especially in view of the at-times conflicting evidences available. To this end, this review aims to provide a critical and up-to-date overview of current treatment options for haemorrhoids, after briefly discussing contemporary views of their aetiology and pathogenesis.

\section{METHODS}

\section{Literature search}

A literature search was performed to identify articles on hemorrhoids. PubMed (1966 to May 2019), Embase (1980 to May 2019), and the Cochrane library (1993 to May 2019) were searched electronically using following search terms: hemorrhoid OR haemorrhoid OR hemorrhoids OR haemorrhoids OR "Hemorrhoid" [Mesh]. In addition, reference lists of relevant articles, reviews and commentaries were manually searched, and experts in the specialty were contacted to identify papers not captured by electronic searches. Studies searched were limited to those performed in humans.

\section{Inclusion and exclusion criteria}

Studies were included if they assessed cohorts of patients who underwent investigations for, or management of, haemorrhoids. Individual case reports were included where unusual complications and their successful management were described.

Studies published in a language other than English were excluded.

All abstracts or titles in the electronic searches were scrutinized by one of the authors (KSN), and full manuscripts of potentially eligible citations were obtained.

These manuscripts were reviewed by 2 independent reviewers (KSN and CJY), and studies meeting the above inclusion and exclusion criteria were selected.

An electronic database proforma was used to extract relevant information from each study. Data extraction was performed by all authors, and then presented in narrative form.

\section{AETIOLOGY AND PATHOGENESIS}

There are 2 vascular arteriovenous plexuses that are important to normal anal canal anatomy, one located in the upper anal canal above the dentate line (internal haemorrhoidal plexus), and the other at the anal verge (external haemorrhoidal plexus).

The internal haemorrhoidal plexus forms 3 discrete anal cushions which are located consistently in the left lateral, right anterior, and right posterior positions ('3-7-11 oclock' in the lithotomy position) [2]. Lying superior to the dentate line, these anal cushions are covered by columnar epithelial cells that have visceral innervation. The cushions are supported by smooth muscle stroma and elastic tissue (sometimes referred to as Treitz's muscle), which help fix them to their proper anatomical position. Specifically, Treitz's muscle comprises 2 distinct parts: the anal submucosal muscle, whose fibres fix the cushions to the 'floor' of the haemorrhoids (i.e., internal sphincter), and the mucosal suspensory ligament (Park's ligament), which penetrates the internal sphincter to fix the cushions to the conjoint longitudinal muscle [3]. The veins that form the internal haemorrhoidal plexus consist of complex dilatations, allowing changes to the size of the cushions which convert the anal lumen into a triradiate slit, assisting anal closure [4]. Accordingly, these anal cushions complement anal sphincter function by providing fine control over the continence of liquid and gas, and contribute up to $15 \%$ of resting anal tone [5]. However, their abnormal enlargement produces haemorrhoidal disease.

The external haemorrhoidal plexus lies below the dentate line in the subcutaneous tissue at the anal verge. It drains via the inferior rectal veins into the pudendal vessels, and thence into the internal iliac vein. This plexus is normally not visible and does not really contribute to the physiology of the anal canal. It is covered by anoderm that is modified squamous epithelium containing pain fibres, thus accounting for the way that external haemorrhoids present and are treated [6].

A widely accepted theory in the pathogenesis of internal haemorrhoids is that fragmentation of Treitz's muscle leads to anal cushion descent. Anal cushions are thus no longer restrained from engorging excessively with blood, and the prolapsed cushion has an impaired venous return. This results in dilation and stasis of the internal haemorrhoidal plexus, and transudation of fluid. Further congestion of these vascular cushions leads to pain and anal spasm that prevent reduction, leading to a vicious cycle of prolapse and progressive swelling of the vascular cushions [7].

Fragmentation of Treitz's muscle may be caused by shearing forces incurred during prolonged and repeated downward stress, often observed with straining at defaecation. Accordingly, risk factors for haemorrhoids are those associated with excessive straining and/or increased intra-abdominal pressure (i.e., constipation, hard stools, pregnancy) $[7,8]$. Human civilisation has adopted the sitting rather than squatting position during defaecation, which does not permit the straightening of the anorectal angle and thus necessitates greater effort and exaggerated intraabdominal pressure for passage of stool [3]. To this end, time spent during defaecation has been linked to the development of haemorrhoids, with one study identifying that patients with proctoscopically confirmed haemorrhoids spent more time during defaecation and reading on the toilet than controls [9]. This has led to the recommendation to limit time spent defaecating to no more than 5 minutes per day [10].

\section{CLASSIFICATION OF HAEMORRHOIDS}

Based on the implicated 'parent' haemorrhoidal plexus, haemorrhoids are classified on their relationship to the dentate line. Internal haemorrhoids originate proximal to the dentate line, and external haemorrhoids originate distal to the dentate line [11]. 
Volume 36, Number 3, 2020

The classic Goligher staging of haemorrhoidal disease refers to internal haemorrhoids [12], which can be classified into 4 degrees: (1) first-degree haemorrhoids protrude into the anal canal lumen but do not prolapse; (2) second-degree haemorrhoids prolapse beyond the anal canal but reduce spontaneously; (3) thirddegree haemorrhoids protrude outside the anal canal on straining and require manual reduction; and (4) fourth-degree haemorrhoids are irreducible and are constantly prolapsed. This classification is therefore a clinical classification with implications on further management. Other classification systems for haemorrhoids have been proposed, but none are as widely adopted as Goligher's [13].

\section{PRESENTATION OF HAEMORRHOIDS}

Haemorrhoids can present with a variety of symptoms, including rectal bleeding, sensation of a prolapsing lesion, anal pain, anal irritation, and/or anal soiling. These symptoms are not specific to haemorrhoidal disease, however, and there is a large differential diagnosis which must be considered lest more serious pathology be missed. Often times, attributing a patient's symptom(s) to haemorrhoids can only be secured after exclusion of these other causes [14].

The most common presenting symptom of haemorrhoids is rectal bleeding, which is usually painless and associated with defaecation. Bleeding is attributed to microtrauma of the vessel wall elicited during defaecation of hard stools, and is exacerbated by congestion of the haemorrhoidal plexus, transferred backwards to the feeding arterioles. Bleeding from haemorrhoids is therefore arterial in origin, explaining its bright red nature [15]. Darker red blood mixed with the stool suggests a more proximal source. Bleeding is usually self-limiting unless the patient is anticoagulated or has a bleeding diathesis. Additionally, the venous hypertension of the diseased anal cushions augments the transudation of fluid, producing what has been referred to as 'anal soiling' (although it has nothing to do with incontinence) and local pruritus. Thrombosed internal haemorrhoids usually present as a very large acutely painful prolapsed haemorrhoid (Fig. 1A). While haemorrhoidal prolapse is usually a chronic phenomenon, acute prolapse can occur where the haemorrhoid becomes trapped by the sphincter outside the anus, leading to obstruction of venous return, thrombosis, and strangulation [16].

Contrary to thrombosed internal haemorrhoids, a thrombosed external haemorrhoid presents as a small well-defined nodule confined to the subcutaneous external haemorrhoidal plexus at the anal verge (Fig. 1B). The patient describes an acutely tender, firm lump at the anal margin which is covered by anoderm and perianal skin richly innervated with somatic pain fibres. Pain builds to a crescendo over hours and is constant for a few days before the pain gradually eases. The lump takes longer to resolve as the clot is absorbed, leaving a small residual skin tag.

\section{DIAGNOSIS OF HAEMORRHOIDS}

A diagnosis of haemorrhoids is confirmed by history and clinical examination, yet the accuracy of diagnosis is variable among cli-
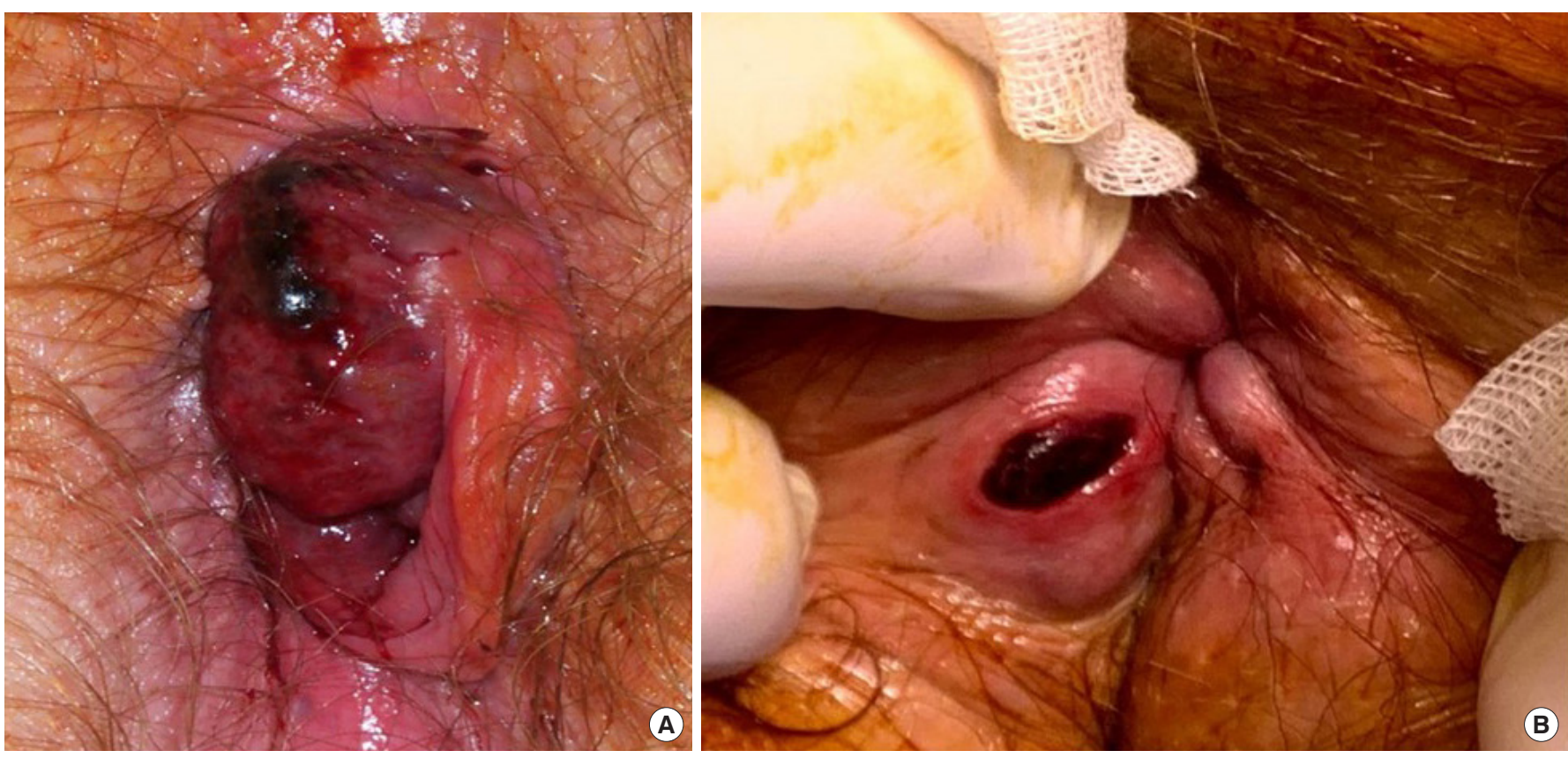

Fig. 1. (A) Thrombosed prolapsed internal haemorrhoid. (B) Complex thrombosed external haemorrhoid, which was found to have spontaneously discharged - this was managed by excision of the thrombus and its underlying external haemorrhoidal plexus. 
nicians outside colorectal surgery. In a study of patients referred to a tertiary colorectal clinic with a diagnosis of 'haemorrhoids', only $65 \%$ of patients were diagnosed accurately by the referrer. The most common misdiagnoses were fissure-in-ano (34\%) and anal skin tag (27\%); occasional misdiagnoses of rectal and anal carcinomas were recorded as well. Patients who presented with a protruding lesion had $73 \%$ higher odds of an accurate diagnosis compared with patients who presented with pain or pruritus [17].

Inspection of the anal margin at rest and with the patient straining will help grade any haemorrhoidal disease. First- and seconddegree haemorrhoids are often only visible with a proctoscope and are accentuated when the patient strains. Where the patient has pain which precludes bedside proctoscopy, examination under anaesthesia may be required to exclude other possible causes such as a fissure, abscess, or anal cancer [18].

Fresh bleeding not associated with any other anal symptoms and without any other colorectal 'alarm' symptoms (e.g., change in bowel habit, abdominal pain, weight loss) or family history of colorectal neoplasia should be investigated with at least a flexible sigmoidoscopy. Complete colonic assessment (colonoscopy or computed tomography $[\mathrm{CT}]$ colonography) is required where the symptom pattern suggests more proximal pathology (e.g., darker red bleeding mixed with stools, anaemia, positive faecal occult blood test, abdominal mass, or tenderness). The threshold to perform a colonoscopy (or CT colonography) is lowered with increasing patient age [19].

\section{TREATMENT}

Once it has been established that a patient's symptoms are attributed to haemorrhoids, a discussion is had with the patient about treatment options. These options include 'no treatment', which for many patients whose symptoms are intermittent, self-limiting, and of minimal inconvenience, is a preferred approach. These patients may simply be concerned as to the implication of their symptoms and may be satisfied with an explanation of their benign diagnosis [19].

Where the patient seeks resolution of their symptoms, however, many options are available, ranging from simple conservative measures to surgical excision of the haemorrhoids. The choice of therapy normally depends on the severity of symptoms and the amount of prolapsing haemorrhoidal tissue.

\section{FIRST-DEGREE HAEMORRHOIDS}

\section{Dietary modifications}

If the haemorrhoids are not prolapsing, nonoperative methods should be attempted first. Patients should be advised to avoid straining at stool. This advice is usually combined with measures to improve bowel function either by laxatives or increasing fluid and fibre intake. In a meta-analysis of the use of fibre (mainly ispaghula husk) for haemorrhoid symptoms, bleeding showed a
$50 \%$ relative risk (RR) reduction in the fibre group (RR, 0.50; $95 \%$ confidence interval [CI], 0.28-0.89) [20].

\section{Topical agents}

There are many topical ointments and suppositories for treating haemorrhoidal symptoms, available over the counter and by prescription. These topical agents typically contain low-dose anaesthetics, steroids, protectants, antiseptics, and astringents [21]. However, there is little evidence to demonstrate any benefit from such applications [22]. Despite this, these topical agents are enormously popular, with countless patients using these preparations and reporting improvement in their anal symptoms [23].

Other forms of treatment that can give more immediate symptomatic relief for first-degree haemorrhoids include rubber band ligation and injection sclerotherapy. However, only cases refractory to nonoperative methods should undergo these more invasive treatments.

\section{SECOND-DEGREE HAEMORRHOIDS}

\section{Rubber band ligation}

Rubber band ligation (RBL) is the technique of choice for seconddegree haemorrhoids and is the most popular nonsurgical intervention. In a recent Dutch study, $90 \%$ of surgeons reported starting with RBL as the first treatment for low-grade haemorrhoidal disease [24].

With the aid of a proctoscope, the target tissue of RBL is the apex of the anal cushion above the dentate, avoiding at all costs the dentate line and any surface with somatic sensation (Fig. 2). If a band is placed too low, the patient will experience immediate pain, and the band should be removed. The idea is to produce cicatrisation at the haemorrhoid apex; as the tissue strangulated by the rubber band necroses and sloughs off (usually within a few days), the wound fibroses and 'fixes' the haemorrhoidal cushion within the upper anal canal, akin to forming new suspensory ligaments for the cushion. The haemorrhoidal tissue is thus prevented from engorging and prolapsing [25].

Significant complications include:

- Pain - although the procedure is relatively painless if the bands are correctly placed above the dentate line, a number of patients still report pain that may persist for some days. The use of local anaesthetic infiltration prior to RBL appears to decrease post-procedure pain [26].

- Bleeding - minor bleeding after the procedure is common. Secondary haemorrhage is unusual but can be spectacular, requiring hospital admission and suture ligation under general anaesthesia. RBL should be avoided in patients on warfarin or clopidogrel, as the risk of secondary haemorrhage is increased in these patients [27].

- Pelvic sepsis - this is fortunately very rare. Sinister clinical features heralding local sepsis are perineal pain, urinary retention, and fever, which may lead to progressive oedema and cellulitis 

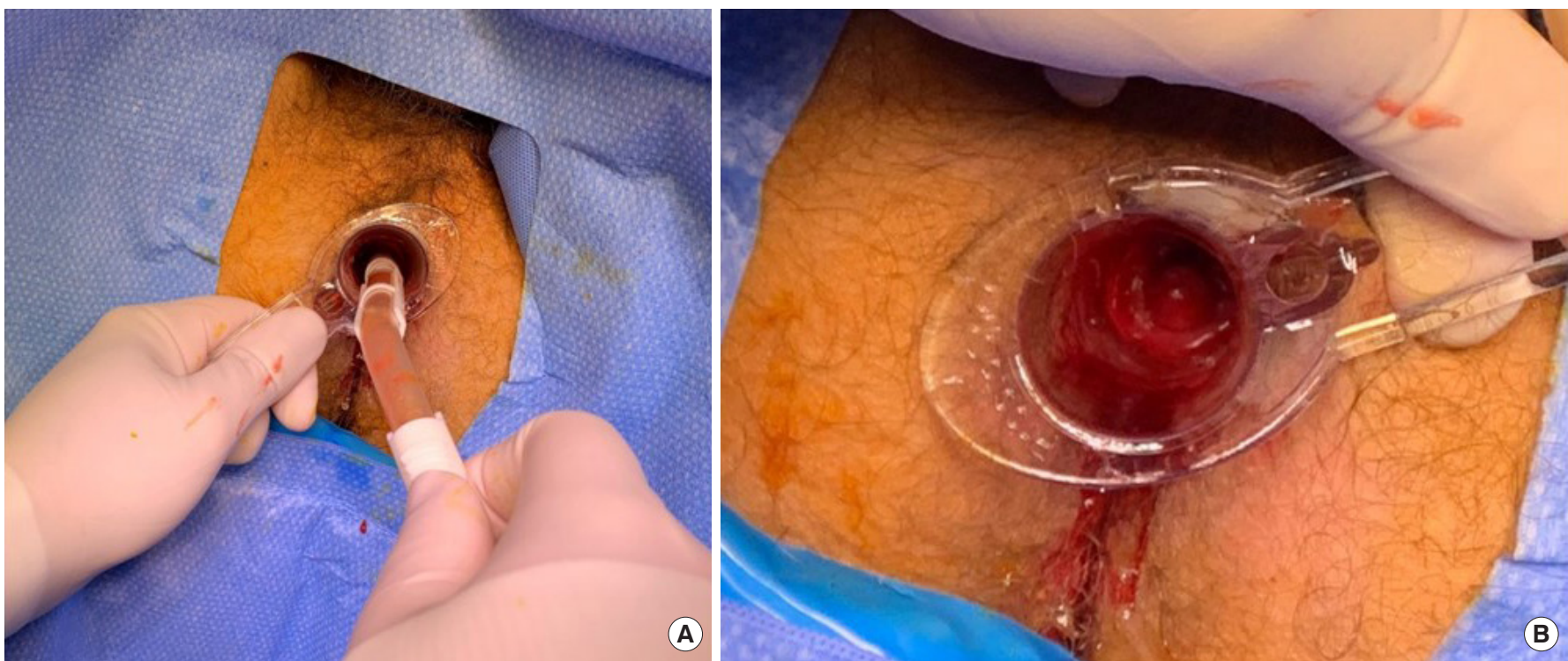

Fig. 2. Rubber band ligation. The target tissue is the apex of the haemorrhoid, well above the dentate line.

affecting the perineum, thighs, and abdomen [27].

RBL has a short-term success rate of about $70 \%$. It should be remembered that RBL is easily repeated and often is offered as a course rather than one-off treatment. In a meta-analysis of 18 studies of outcome after haemorrhoid therapy, RBL was superior to injection sclerotherapy as treatment for all haemorrhoids with no difference in the complication rate. Patients treated with RBL were less likely to require further therapy than those treated with sclerotherapy [28]. Long-term results for RBL are less well published, although one recent systematic review reported rates of bleeding recurrence to range between $10 \%$ and $46 \%$ [29].

\section{Injection sclerotherapy}

Injection sclerotherapy is performed using a purpose designed Gabriel syringe, which allows injection of $2-3 \mathrm{~mL}$ of a sclerosant (usually 5\% phenol in almond oil) at each of the 3 haemorrhoidal sites. Sclerosant is placed in the submucosa around the pedicle of the haemorrhoid at the junction of the normal pink rectal mucosa and the purplish mucosa of the cushion. The result is local inflammation which eventually leads to reduced blood flow into the haemorrhoids. Similar to RBL, fibrosis of the area draws minor prolapse back into the anal canal. Particular care must be taken if injecting the midline anteriorly though, because of the proximity of the prostate and urethra in the male and the vagina in the female [30].

While there appears to be short-term benefit with injection sclerotherapy in terms of controlling haemorrhoidal bleeding, its long-term outcomes are poor. In one randomised trial, haemorrhoidal symptoms at 6 months were no better following injection sclerotherapy than if the patient had been treated with bulk laxative alone [31]. One other study measured the medium- to long- term outcome following large dose injection sclerotherapy and at 4-year follow-up, found that less than one-third of patients had been cured; the majority of patients reported that their symptoms remained either unchanged or had deteriorated [32]. With its disappointing long-term outcomes, the role of injection sclerotherapy remains limited.

\section{THIRD-DEGREE HAEMORRHOIDS}

\section{Haemorrhoidectomy}

Third-degree haemorrhoids have traditionally been removed by haemorrhoidectomy. A variety of techniques have been described, but some (such as the Whitehead circumferential excision) have been abandoned. Currently, 2 methods of haemorrhoidectomy are popular: the (Milligan and Morgan) open excision, and the (Ferguson) closed haemorrhoidectomy. In both approaches, the underlying principle is to remove the swollen haemorrhoid tissue from outside and inside the anal canal, preserving sufficient mucosa and anoderm to maintain function of the anal canal. Haemorrhoidectomy can be performed with scissors or diathermy [33]; more recently, other energy devices have been used including ultrasonic technology (Harmonic scalpel) [34], laser [35], and radiofrequency devices [36], with reports that these newer technologies cause less postoperative pain and allow quicker return to normal activity.

\section{Open (Milligan-Morgan) haemorrhoidectomy}

Traditionally, the patient is placed in the lithotomy position, and the procedure is performed under general anaesthesia. Examination of the anal canal with a Pratt retractor confirms the position of the haemorrhoid(s) to be removed. The skin-covered external 


\section{Coloproctology $\quad$ annals of $\quad$ ang-Seong $\mathrm{Ng}$, et al.}

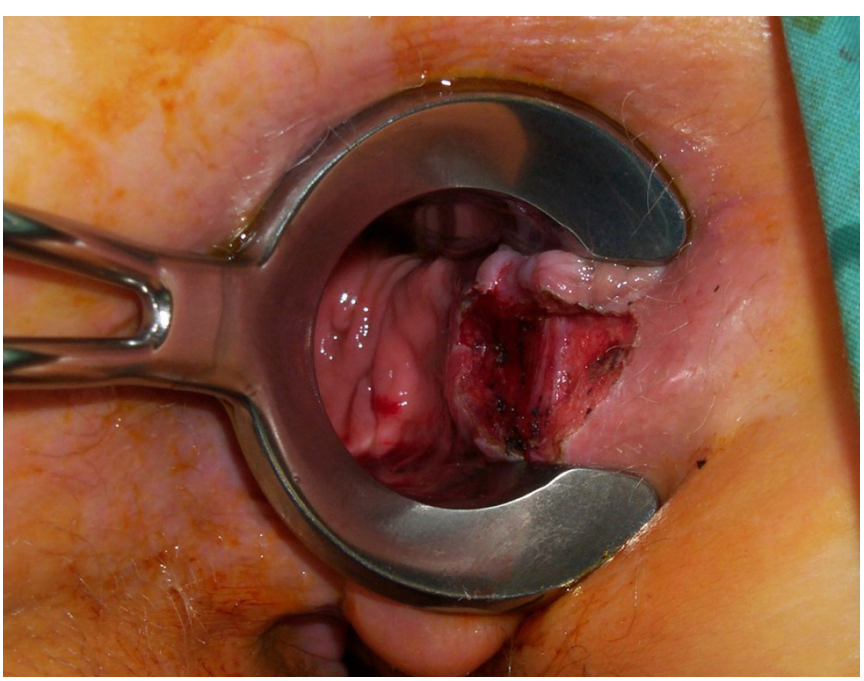

Fig. 3. An open haemorrhoidectomy wound, seen using a Fansler proctoscope. The fibres of the external and internal sphincter muscles are identified and preserved. In this patient, only a single pedicle haemorrhoidectomy was performed.

element of the haemorrhoid(s) to be excised is grasped with an artery forcep and drawn downward and outward to expose the lower pole of the mucosal-covered part of the haemorrhoid. The mucosal component of each haemorrhoid is then grasped with a second artery clip and drawn out to expose the whole of the haemorrhoid to be removed. A V-shaped incision is then made in the perianal skin, and the incision deepened and extended across the mucocutaneous junction of the anal canal. The haemorrhoid is then carefully separated from the underlying ring of external sphincter muscle at the anal margin and internal sphincter within the anal canal (Fig. 3). In this manner, a haemorrhoidal pedicle is developed, with its base in the upper anal canal. The pedicle is transfixed with a heavy absorbable suture and ligated, before being excised with scissors. The procedure is repeated at each of the other haemorrhoid sites. Care is taken throughout the procedure to maintain adequate mucocutaneous bridges between each of the excision sites. Failure to do this can lead to a large circumferential wound, which will heal with considerable stenosis. The idea is to leave 3 pear-shaped wounds on the anal margin [37].

Performed properly, the Milligan-Morgan haemorrhoidectomy produces good results and has stood the test of time. In a systematic review comparing haemorrhoidectomy with RBL, complete remission of haemorrhoidal symptoms was better after haemorrhoidectomy (RR, 1.68; 95\% CI, 1.00-2.83), and few patients required retreatment after haemorrhoidectomy (RR, 0.20 ; $95 \% \mathrm{CI}$, $0.09-0.40)$ [38]. A separate study of the long-term results of this operation showed that after at least 5-year follow-up, two-thirds of patients were happy with the results of the operation; notably though, in this cohort of over 400 patients, one-third reported anal incontinence, one-quarter of whom dated the onset of incon- tinence to the operation [39].

\section{Closed (Ferguson) haemorrhoidectomy}

Proponents of closed haemorrhoidectomy argue this approach speeds up healing by closing the defects in the anal canal, and minimises the risk for stenosis which may complicate healing by second intention of large anal wounds.

The excision of the haemorrhoid is performed as for an open haemorrhoidectomy. In contrast to the open approach, the resulting defect is closed with a running absorbable suture. Suturing commences at the apex, where the rectal mucosa is fixed to the underlying muscle to prevent further prolapse. The anal mucosa can also be fixed to the internal sphincter by including small bites of the muscle. Suturing continues out onto the perianal skin to produce a longitudinal suture line, leaving a 5-mm opening for drainage [40]. The procedure is repeated until all haemorrhoids have been dealt with. Invariably, less tissue is removed at each subsequent site, and again, care is taken to preserve as much anoderm as possible to allow the wounds to be closed without tension.

Whether to perform an open or closed haemorrhoidectomy is largely a matter of surgeon preference and training. A number of trials comparing the 2 techniques have been published but many trials suffer from small numbers and short follow-up. One Swedish multicentre trial [41] randomised 115 patients to undergo open haemorrhoidectomy and 110 patients to closed haemorrhoidectomy. There was no difference in level of pain postsurgery or in rate of complications, and at 1-year postsurgery, a similar proportion of patients in each group experienced recurrent haemorrhoidal symptoms (15.6\% vs. 17.6\%). In 2 separate meta-analyses, open and closed haemorrhoidectomies were found to have similar outcomes; the only differences were that the open approach was more quickly performed, while closed haemorrhoidectomy wounds showed faster healing by an average of approximately one week [42] and had a lower risk of postoperative bleeding [43].

\section{Ligasure haemorrhoidectomy}

The principles of Ligasure haemorrhoidectomy are similar to those of closed haemorrhoidectomy and involve excision of the excess haemorrhoidal tissue after first achieving sealing and haemostasis with a bipolar electrothermal sealing device. It is postulated that sealing of haemorrhoidal tissue in between the Ligasure forceps is achieved with minimal collateral thermal spread and limited tissue charring through use of active feedback control over the power output, and proponents of this approach argue this should result in diminished postoperative pain.

The operation is performed under general anaesthesia. An anal retractor is inserted and the external part of the haemorrhoid to be removed is grasped with forceps and lifted into the anal canal. The jaws of the Ligasure instrument are closed across the base of the haemorrhoid, and the machine is activated until sealing oc- 
curs. The haemorrhoidal tissue above the sealing point is excised, and the process is repeated up the anal canal until the haemorrhoid has been completely removed, leaving a thin strip of coagulated and sealed anoderm along the length of the anal canal. The process is repeated for each haemorrhoid to be removed.

Ligasure haemorrhoidectomy has been assessed in a number of randomised trials. One Cochrane review [44] found that pain and analgesic requirements during the first 7 days were less after this procedure than following conventional excision, but the difference was lost by day 14 . Hospital stay was similar, as were complication rates. In another recent meta-analysis specifically comparing Ligasure haemorrhoidectomy to Ferguson haemorrhoidectomy, the use of Ligasure was associated with lower pain scores, shorter operating times, and lower volumes of blood loss [45]. It would appear that there are some short-term advantages to Ligasure haemorrhoidectomy, but these need to be offset against the extra expense of the procedure.

\section{Complications of haemorrhoidectomy}

Pain: Haemorrhoidectomy is recognised to be painful, and a variety of manoeuvres have been employed to reduce postoperative pain. Commencing laxatives prior to operation seems appropriate to prevent postoperative constipation. Numerous meta-analyses have evaluated the effects of various adjuncts to oral analgesics (nonsteroidal anti-inflammatory drugs, paracetamol and opiates) to control postoperative pain. Local anaesthetic infiltration (pudendal nerve block) has been shown to significantly improve immediate postoperative pain $[46,47]$. Glyceryl trinitrate is thought to effect a temporary 'chemical sphincterotomy' [48] and increase anodermal blood flow in the first 2 postoperative weeks following haemorrhoidectomy. It improves pain, healing [49] and resumption of daily activities at the expense of an increased incidence of headaches [50]. Similar results have also achieved with local calcium channel blockers [51, 52], botulinum toxin A [53], and topical baclofen therapy [54]. The effects of oral and topical metronidazole on postoperative pain have been assessed in numerous comparative studies with conflicting results [55-58], although 2 recent meta-analyses have shown metronidazole to be a cheap, safe, and effective intervention for reducing postoperative pain following haemorrhoidectomy, facilitating an earlier return to normal activity $[59,60]$. However, topical and oral routes of administration for metronidazole have yet to be compared in a randomised trial.

Bleeding: Primary bleeding arises from the vascular pedicle or the cut edges of the mucosa, and is usually due to inadequate intraoperative haemostasis. Simple pressure may be all that is required to stop the bleeding. Brisker bleeding requires examination under anaesthesia and suture ligation. Submucosal adrenaline injection has been shown to be effective for addressing bleeding after haemorrhoidectomy [61].

Secondary haemorrhage usually arises as a consequence of infection in the haemorrhoidectomy wound and can occur between days 7 and 14 postoperatively. It affects approximately $5 \%$ of patients undergoing conventional haemorrhoidectomy [62]. Bleeding is often brisk and will require admission to hospital, fluid resuscitation, and examination under anaesthesia. Antibiotics should be prescribed and continued for a few days after the haemorrhage ceases.

Urinary retention: Urinary retention is more common in male patients than female patients and may be due to reflex spasm of the urinary sphincter in response to pain. Patients with pre-existing symptoms of urinary outflow obstruction are more prone. In one series, over one-third of patients following haemorrhoidectomy experienced postoperative urinary retention, with extent of excision (i.e., number of haemorrhoidal quadrants excised) being a strong predictor of retention [63].

Infection: Infection following haemorrhoidectomy is unusual, despite high bacterial contamination of the operative field. Submucosal abscess with subsequent fistula formation can occur after closed haemorrhoidectomy. Rare cases of fulminant infection after haemorrhoidectomy usually involve patients who are immunosuppressed. However, as the consequences of infection can be dramatic, a high index of suspicion should be maintained in any patient who is unwell and experiencing increasing pain following haemorrhoidectomy [64].

Anal stenosis: Development of anal stenosis reflects excessive removal of anoderm with cicatrisation of the anal canal during healing. It is a complication of technical failure to leave sufficient mucocutaneous skin bridges and is seen in less than $5 \%$ of haemorrhoidectomies [65]. Simple dilatation may be all that is required to correct the problem, but advancement flap anoplasty is sometimes required to correct the stenosis (Fig. 4).

Faecal incontinence: Rates of continence disorders following haemorrhoidectomy are reported to vary between $0 \%$ and $28 \%$ [66]. Causes include changes in mucosal sensitivity and anal sphincter pressures following surgery, changes in the symmetry and closure of the anal canal following removal of haemorrhoidal tissue, and occult damage to the sphincter complex during haemorrhoidectomy. One study identified that internal sphincter damage was detectable endosonographically in over $5 \%$ of patients following open haemorrhoidectomy [67].

\section{Stapled haemorrhoidopexy}

While conventional haemorrhoidectomy deals with symptoms alone by excising the anal cushions once they bleed or are painful, it does not act on the pathophysiological mechanism underlying haemorrhoidal disease, that is, the descent of the mucosal anal cushions. By contrast, stapled haemorrhoidopexy (also known as 'procedure for prolapse and haemorrhoids [PPH]') excises a ring of rectal mucosa above the haemorrhoids rather than the haemorrhoids themselves, and aims to return the prolapsed distal mucosa and reconstitute normal anatomy and physiology of the haemorrhoidal plexus. At the same time, there is disruption of the distal branches of the superior rectal arteries feeding the haemorrhoidal 

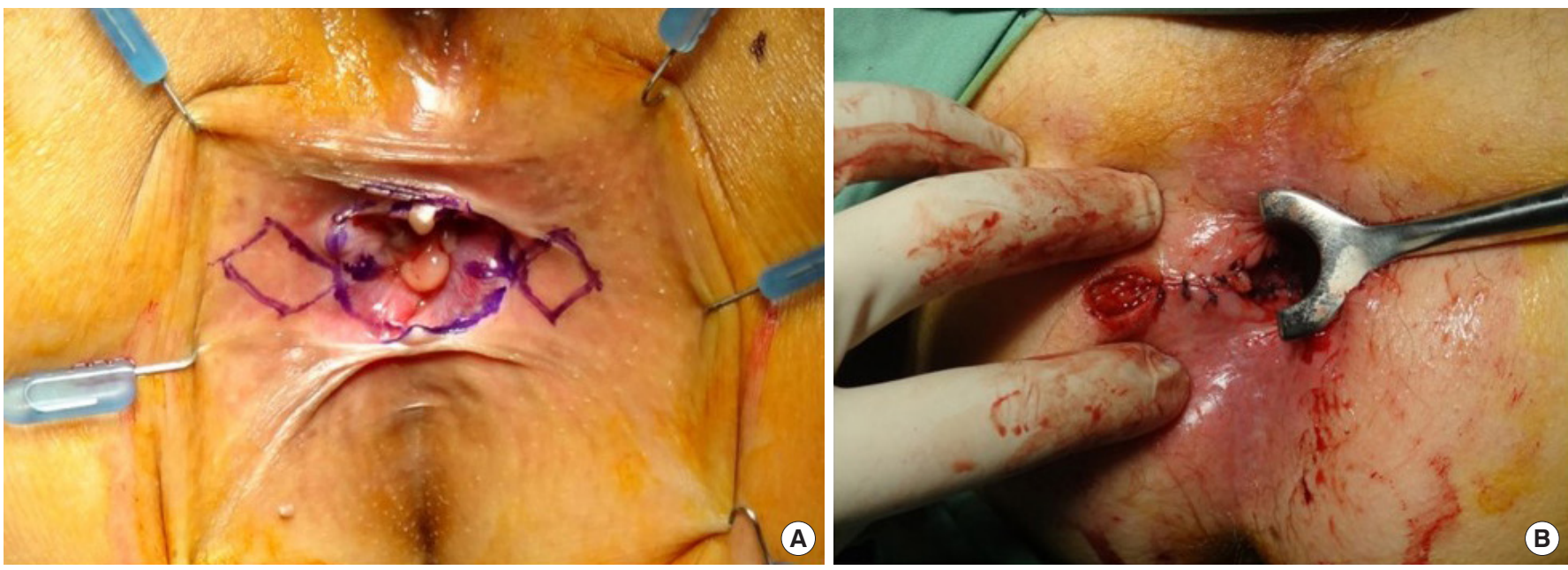

Fig. 4. Bilateral advancement anoplasty flaps. This patient had severe anal stenosis following a previous 3 pedicle haemorrhoidectomy. (A) Bilateral island flaps are raised close to the anal verge, and (B) utilized as anocutaneous advancement flaps.

plexus. Once reduced, the engorged haemorrhoidal tissue will decongest and shrink. It has been postulated that stapled haemorrhoidopexy achieves a more physiological result by restoring the displaced haemorrhoidal tissue to its normal anatomical position as opposed to excising it, recognising the importance of the haemorrhoidal cushions in faecal continence.

Stapled haemorrhoidopexy is most suited for patients with significant reducible mucosal prolapse and large internal haemorrhoids which have not responded to banding or sclerotherapy. The operation is performed with a modified circular stapling instrument (PPH-03 - Ethicon Endo Surgery) under general anaesthesia. A mucosal purse-string suture is placed at least $2-\mathrm{cm}$ cephalad of the dentate line; each bite of the suture includes only mucosa and not rectal muscle, and the needle is inserted immediately adjacent to the last exit site such that the suture is completely buried in the submucosal plane. Care should be taken that each bite of suture is the same distance from the dentate line to avoid "spiralling" of the suture. Once the suture is placed, the opened gun is inserted such that the anvil lies above the level of the pursestring. The suture is then tied around the shaft of the instrument, which is then closed tight, and the gun fired. The staple line is then inspected and any bleeding point under-run with an absorbable suture [68] (Fig. 5).

Stapled haemorrhoidopexy is usually a quick operation to perform and comparison with conventional haemorrhoidectomy in randomised controlled trials and systematic reviews reveals significant reduction in analgesic requirements, shorter hospital stays, and quicker recovery with this approach [69-71]. This is somewhat expected, given that rectal rather than anal tissue is removed.

That said, some have called into question the long-term efficacy of stapled haemorrhoidopexy in treating haemorrhoids [72], with meta-analyses concluding that the technique is associated with higher recurrence rates than conventional haemorrhoidectomy, thus necessitating reoperation $[73,74]$. This appears to be a problem especially for stapled haemorrhoidopexies performed for fourth-degree haemorrhoids [75], emphasising the importance of patient selection when using this technique. Performers of stapled haemorrhoidopexy should also be aware of its potential to produce significant serious morbidity and even mortality in the immediate postoperative period [76]. These complications, including gross pelvic, retroperitoneal and perineal sepsis, are rare and reported mostly as case reports, but seriously endanger the patient's life for what is treatment of an otherwise benign disease. Symptoms such as abdominal pain, urinary retention and fever may herald these serious complications [77]. It is believed that such complications derive from technical error where excessive muscle is incorporated in the 'doughnut' resulting in a full-thickness (or near full-thickness) staple line with consequent risk of anastomotic leakage; for this reason, it has been suggested that submucosal injection of saline at the planned purse-string site might reduce the risk of incorporating excessive muscle into the stapler housing [78]. Finally, distressing new symptoms such as tenesmus affect up to one-third of patients long-term [79], and are probably related to the mucosal stimulation of the staple metallic foreign bodies which sometimes require a second operation to remove.

\section{Transanal haemorrhoidal dearterialization}

Transanal haemorrhoidal dearterialization (THD), also known as haemorrhoidal artery ligation, is a newer approach to the treatment of haemorrhoids. It is a nonexcisional surgical technique that aims to interrupt arterial flow to the haemorrhoidal plexus by means of Doppler-guided localisation of the feeding vessels and 
(A)

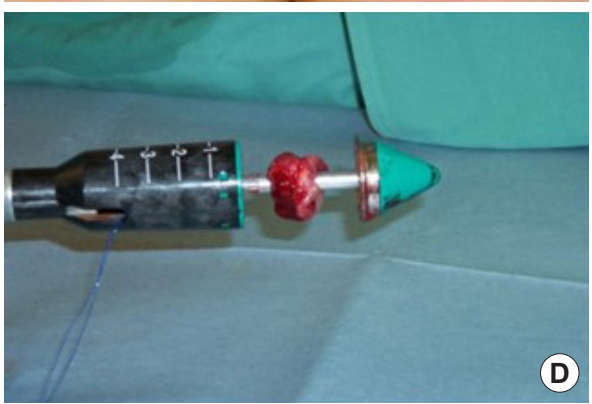

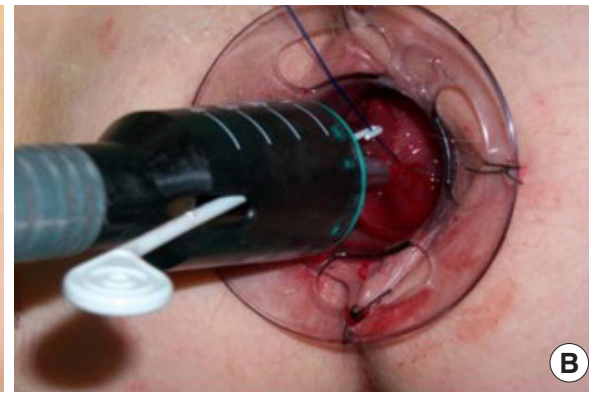
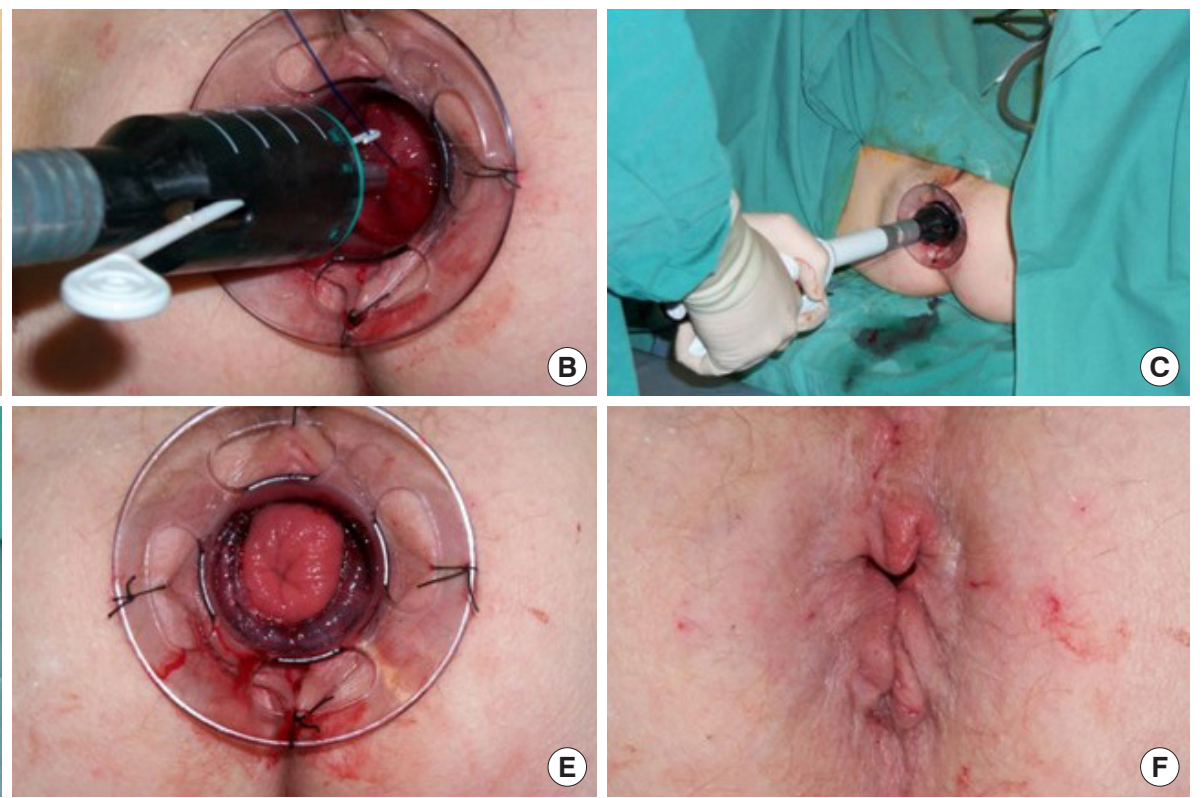

Fig. 5. Stapled haemorrhoidopexy. (A) This patient presented with circumferential third-degree haemorrhoids. (B) Following application of a mucosal pursestring suture, the PPH-03 stapler is positioned. (C) The stapler is fired. (D) The excised rings of rectal mucosa are inspected. (E) The staple line is inspected for any defects or bleeding. (F) Immediately following stapled haemorrhoidopexy, the prolapsed haemorrhoidal tissue is observed to have reduced substantially.

per anal ligation. On average, there are 6 haemorrhoidal arteries terminating from the superior rectal artery and reaching the haemorrhoidal zone, typically located at the odd-numbered positions of a clockface [80]; these arteries are the target for THD.

The procedure is performed under general anaesthesia using a specifically designed proctoscope incorporating a Doppler transducer. At the distal end of the Doppler transducer, there is a small window that allows the accurate placement of the sutures by localisation of all the terminal branches of the haemorrhoidal arteries, which are then sequentially sutured, transfixed, and ligated with an absorbable suture [81] (Fig. 6). The sutures are placed about $4 \mathrm{~cm}$ above the dentate line. Once a $360^{\circ}$ dearterialization is completed, the rectal mucosa is plicated in 3 or 4 quadrants dealing with the largest prolapsing components. The plication commences as far in as the proctoscope allows, normally 4 to $5 \mathrm{~cm}$ proximal to the dentate line. A continuous suture is then inserted toward the dentate line taking the mucosa and submucosa. The suture is stopped at about $5 \mathrm{~mm}$ from the dentate line taking care not to catch the anal mucosa to avoid postoperative pain [81].

THD aims to correct the physiology of the haemorrhoidal plexus by restoring normal anatomy rather than excising disrupted tissue. The reduction of the arterial inflow (dearterialization) leads to shrinkage of the anal cushions, and an elimination of the mucosal prolapse (mucopexy, MP) looks to improve the venous drainage of the internal haemorrhoidal plexus, thus reducing recurrence. Furthermore, repositioning the haemorrhoidal cushions rather than excising them maintains their physi- ological role in the continence mechanism [82].

The fact that THD involves surgery of tissues above the sensitive anoderm minimises postoperative pain with quicker recovery times [83], allowing the majority of these cases to be performed as day-only procedures [84]. In a recent multicentre randomised controlled trial comparing THD to ligasure haemorrhoidectomy for the treatment of third- and fourth-degree haemorrhoids, analgesia consumption continued for an average of 5 days longer in the Ligasure haemorrhoidectomy group (mean 15.2 days vs. 10.1 days, $\mathrm{P}=0.006$ ) [85]. THD has also been associated with significant shorter hospital stays compared with conventional haemorrhoidectomy (3.3 days vs. 5.1 days, $\mathrm{P}<0.001$ ) [86]. Furthermore, THD has been suggested as an intervention for haemorrhoids that can be safely performed on anticoagulated patients without cessation of blood thinners; one retrospective study showed no difference in postoperative bleeding rates between THD patients who were not anticoagulated and those who continued anticoagulation perioperatively [87].

Recently, the role of THD in the management of haemorrhoids has been scrutinized with the results of the HubBLe trial (haemorrhoidal artery ligation versus rubber band ligation trial), which was a multicentre randomised trial comparing THD with RBL for the treatment of second- and third-degree haemorrhoids. Oneyear recurrence in the THD group was 30\%, compared with $49 \%$ after RBL; however, the main reason for difference was the number of extra procedures required to achieve improvement/cure. If a single THD was compared with multiple RBL's (as would be a 

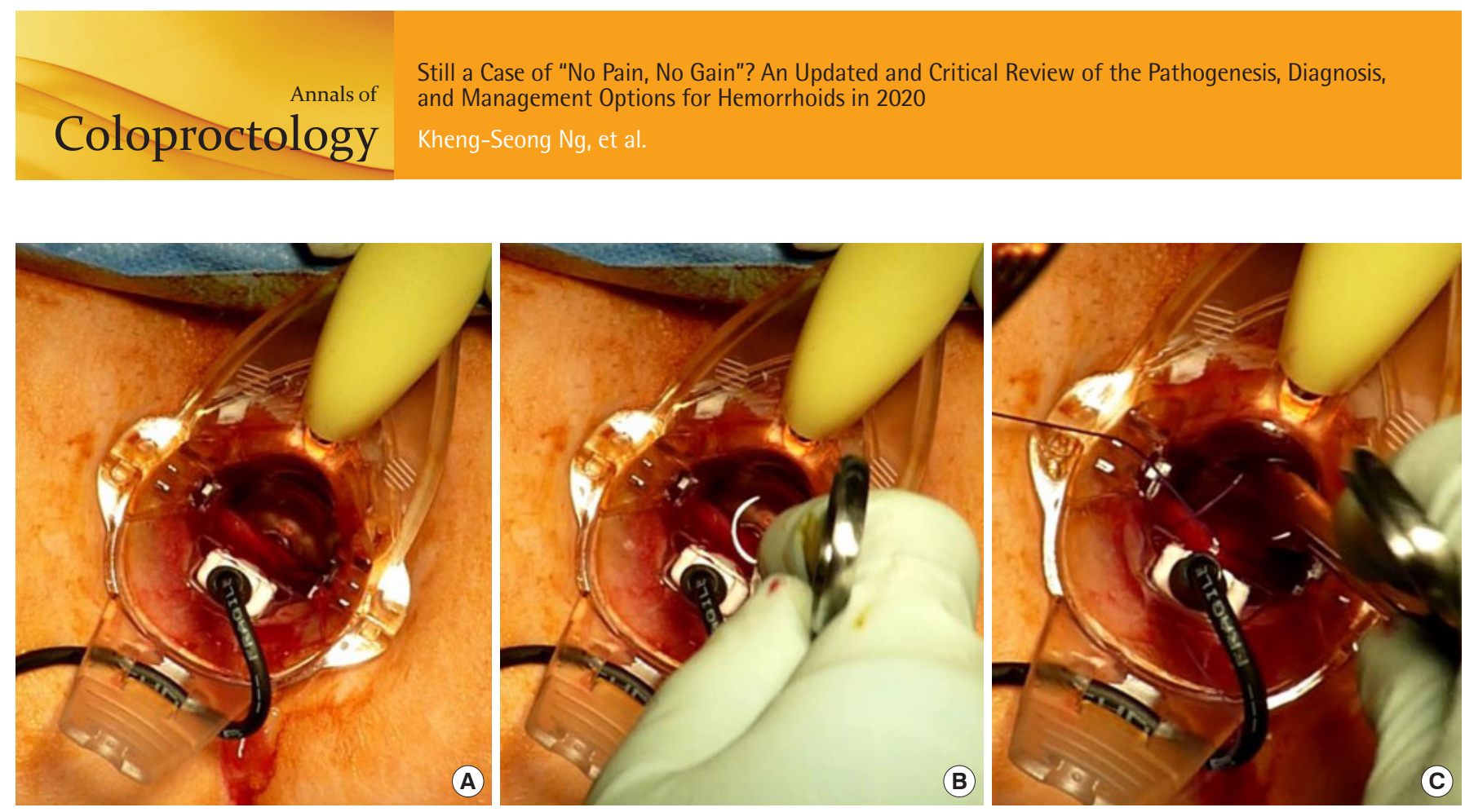

Fig. 6. Transanal haemorrhoidal dearterialization. (A) A transanal haemorrhoidal dearterialization proctoscope with doppler transducer is positioned, on this occasion localising the superior rectal artery branch at 7 oclock. (B, C) 3-0 vicryl suture ligation of vessel through the window of the proctoscope.

usual clinical scenario), then only $37.5 \%$ recurred in the RBL arm, a nonsignificant result (adjusted odds ratio [aOR], 1.35; 95\% CI, $0.85-2.15)$. Notably, pain was also less severe and of shorter duration in the RBL group. The authors of that trial thus concluded that THD was more expensive and unlikely to be a cost-effective treatment for second- and third-degree haemorrhoids [88]. The results of this trial may well change perceptions regarding the utility of THD in the face of a credible alternative, i.e., a 'course' of banding, which has been proven by HubBLe to be a safe and more cost-effective means of alleviating prolapse and bleeding in a majority of patients. THD may instead find a niche role as a second-line treatment for patients who relapse following a course of RBL and do not wish to have a haemorrhoidectomy [89].

\section{FOURTH-DEGREE HAEMORRHOIDS}

Conventional haemorrhoidectomy remains the mainstay treatment for fourth-degree haemorrhoids, as it addresses the irreducible prolapse and any hypertrophic skin tags [90]. Stapled haemorrhoidopexy is not recommended for fourth-degree haemorrhoids because recurrence can be as high as 50\% [91]. Some authors have suggested that THD may also have a role in the treatment of advanced haemorrhoidal disease [92], but recurrence rates are higher in these cases. In one systematic review, recurrence rates following THD for fourth-degree haemorrhoids were as high as $59.3 \%$ [80]. In general, newer technologies seek to reduce postoperative pain and speed up postoperative recovery, at the expenses of increased costs and likely increased recurrence rates (Table 1).

\section{THROMBOSED INTERNAL HAEMORRHOIDS}

Traditionally, conservative management has been advocated for prolapsed thrombosed internal haemorrhoids, on the basis that their natural history is self-limiting and symptoms can be expected to resolve within a couple of weeks. Patients often find stool softeners, sitz baths, ice packs, and oral/topical analgesia aid symptom resolution. There have also been concerns regarding increased risks of anal stenosis, sphincter damage, and portal pyaemia following acute surgical intervention [93], thus prompting many surgeons to shy away from the emergency haemorrhoidectomy. However, following conservative management, recurrent symptoms are expected in nearly $90 \%$ if no subsequent treatment is offered [94], prompting some authors to argue for emergency surgery in almost all patients [16].

\section{THROMBOSED EXTERNAL HAEMORRHOIDS}

Treatment of thrombosed external haemorrhoids depends on the point at which the patient seeks help. After 72 hours, the discomfort of any surgery often exceeds the relief provided by it and in this phase of resolution, surgery should be avoided. Within the first 72 hours though, tender thrombosed external haemorrhoids can be surgically removed. The options lie between excision or incision of the haematoma. With excision, an elliptic incision is made around the haematoma, and the clot and entire diseased haemorrhoidal plexus is removed in one piece. Simple incision can be performed to drain the clot, but this is associated with a significant rate of rethrombosis. For this reason, many now recommend excision of the entire thrombus and external haemor- 
Table 1. Overview of treatment options for second and third-degree hemorrhoids

\begin{tabular}{|c|c|c|c|c|}
\hline Degree of hemorrhoids & Treatment option & Pros & Cons & Comments \\
\hline 2nd degree & Rubber band ligation (RBL) & $\begin{array}{l}\text { "Easy-to-do" } \\
\text { Feasible in outpatient clinic } \\
\text { Easy to repeat if needed, short- } \\
\text { term success rate } 70 \% \text { [28] }\end{array}$ & $\begin{array}{l}\text { Significant pain if placed below } \\
\text { dentate line) } \\
\text { Minor bleeding may be experi- } \\
\text { enced with potential for more } \\
\text { significant bleeding }\end{array}$ & $\begin{array}{l}\text { Frequently used as first-line treatment [24] } \\
\text { Not recommended under warfarin/clopi- } \\
\text { dogrel (increased bleeding risk) [27] } \\
\text { Meta-analysis shows superiority compared } \\
\text { to sclerotherapy [28] }\end{array}$ \\
\hline 2nd degree & Injection sclerotherapy & $\begin{array}{l}\text { "Easy-to-do" } \\
\text { Feasible in outpatient clinic } \\
\text { Short-term benefits especially } \\
\text { for bleeding hemorrhoids }\end{array}$ & $\begin{array}{l}\text { Recent studies show poor long- } \\
\text { term outcomes }[31,32]\end{array}$ & Limited role in today's practice \\
\hline 3rd degree & $\begin{array}{l}\text { Open (Milligan-Morgan) } \\
\text { hemorrhoidectomy }\end{array}$ & $\begin{array}{l}\text { "Easy-to-teach" procedure } \\
\text { Good long-term results [39] } \\
\text { Quicker compared to closed } \\
\text { technique [42] }\end{array}$ & $\begin{array}{l}\text { Limited number of hemorrhoids } \\
\text { can be resected - danger of } \\
\text { stenosis }(<5 \%) \text { [65] } \\
\text { Reports of postoperative inconti- } \\
\text { nence [39] } \\
\text { Postoperative pain } \\
\text { Secondary bleeding in up to 5\% } \\
\text { of patients [62] }\end{array}$ & $\begin{array}{l}\text { Good long-term results (low recurrence } \\
\text { rates) [39] } \\
\text { Equivalent results to closed technique [41] } \\
\text { Still a viable option for 3rd degree hemor- } \\
\text { rhoids }\end{array}$ \\
\hline 3rd degree & $\begin{array}{l}\text { Closed (Ferguson) } \\
\text { hemorrhoidectomy }\end{array}$ & $\begin{array}{l}\text { "Easy-to-teach" procedure } \\
\text { Faster wound healing compared } \\
\text { to open [42] } \\
\text { Lower risk of bleeding compared } \\
\text { to open } \\
\text { Lower risk of stenosis as no sec- } \\
\text { ondary healing of big open } \\
\text { wounds [43] }\end{array}$ & $\begin{array}{l}\text { Longer procedure compared to } \\
\text { open technique } \\
\text { Postoperative pain } \\
\text { Secondary bleeding in up to 5\% } \\
\text { of patients [62] } \\
\text { Reports of postoperative inconti- } \\
\text { nence [39] }\end{array}$ & $\begin{array}{l}\text { Good long-term results (low recurrence } \\
\text { rates) [39] } \\
\text { Equivalent results to open technique (po- } \\
\text { tential advantages see pros) [41] } \\
\text { Still a viable option for 3rd degree hemor- } \\
\text { rhoids }\end{array}$ \\
\hline 3rd degree & Ligasure hemorrhoidectomy & $\begin{array}{l}\text { Short operating time } \\
\text { Low volumes of blood loss } \\
\text { Lower pain scores than formal } \\
\text { hemorrhoidectomy in first } \\
\text { postoperative week [45] }\end{array}$ & Expensive equipment & $\begin{array}{l}\text { In authors opinion - not to be recom- } \\
\text { mended as standard use (cost/benefit } \\
\text { ratio) }\end{array}$ \\
\hline 3rd degree & $\begin{array}{c}\text { Transanal Haemorrhoidal } \\
\text { Dearterialisation (HAL) }\end{array}$ & $\begin{array}{l}\text { Minimal postoperative pain, } \\
\text { quick recovery time, easily } \\
\text { doable as day procedure } \\
\text { [83-84] } \\
\text { Good treatment option for pa- } \\
\text { tients under blood thinners - } \\
\text { bleeding risk seems not in- } \\
\text { creased [87] }\end{array}$ & $\begin{array}{l}\text { High postoperative recurrence } \\
\text { rates reported (up to 30\% at } \\
\text { 1-year postoperation) [88] }\end{array}$ & $\begin{array}{l}\text { Newer technique, nonexcisional, aims to } \\
\text { interrupt arterial bloodflow to } \\
\text { Hemorrhoidal plexus } \\
\text { HubBLe-Trial: multiple RBL showed similar } \\
\text { treatment efficacy as HAL, in addition } \\
\text { less pain and shorter procedure in RBL. } \\
\text { Authors question cost-effectivity for HAL } \\
\text { [88] } \\
\text { Might have a role in anticoagulated pa- } \\
\text { tients/patients who do not want a formal } \\
\text { hemorrhoidectomy and who recur after } \\
\text { RBL [89] }\end{array}$ \\
\hline
\end{tabular}


rhoidal vessels beneath [95].

\section{NEWER TECHNIQUES}

\section{Radiofrequency ablation}

Radiofrequency ablation (RFA) is a relatively new modality for haemorrhoidal treatment. A specially designed probe connected to a radiofrequency generator is inserted into the haemorrhoid, or a ball electrode is rolled over the surface of the haemorrhoid, effecting thermocoagulation of the haemorrhoid. By this method, the vascular components of haemorrhoids are reduced, and the haemorrhoid fixed to the underlying tissue by subsequent fibrosis. A study from 2019 reporting on 27 patients with second to fourth-degree haemorrhoids treated with RFA and concluded that this treatment option is safe, easy to perform and enables an early return to work/normal activities. A low (4\%) recurrence rate was shown after 20-month follow-up [96]. Gupta et al. [97] analysed a series of 600 patients with prolapsing haemorrhoids, which were treated with RFA and plication. They concluded that the procedure could be done on an outpatient basis and found well manageable postoperative pain scores as well as rapid return to work. In terms of complications, no patient reported continence disturbances, prolapse, or stenosis; however, $60 \%$ of patients reported some degree of postoperative bleeding. Another group presented good long-term results combining RFA with RBL [98]. RFA, alone or in combination with other nonexcisional, minimalinvasive techniques, might be an attractive future outpatient (walk-in, walk-out) treatment option. Randomised controlled trials will be needed to more clearly define its utility.

\section{Laser}

The use of laser for treatment of haemorrhoids has been described in haemorrhoidectomy and haemorrhoidal coagulation [99]. Recently, its role has extended to haemorrhoidal dearterialization, following the same rationale as THD. Acronymised as 'HeLP' (hemorroidal laser procedure), the procedure was first described in 2011 [100] and utilizes a 980-nm diode laser to cause shrinkage of the terminal branches of the superior rectal artery without the need of sutures. As with THD, the arterial branches are identified with a doppler transducer and closed with a laser beam ( 5 pulsed shots) approximately $3 \mathrm{~cm}$ above the dentate line. Initial studies suggest HeLP to be a safe procedure with minimal postoperative pain, effective most for second- and third-degree haemorrhoids with minimal mucosal prolapse [101]. A recent randomised controlled trial compared 3 groups of 40 patients treated by laser hemorrhoidoplasty (LHP), excisional hemorrhoidectomy (EH) or sutured MP. Recurrence rates after 1 year were $0 \%$ in the EH group, $10 \%$ in the LHP, and $22 \%$ in the MP group. LHP showed the shortest procedure time, was significantly less painful than $\mathrm{EH}$ and return to work was possible 15 days earlier. Despite higher recurrence rates, LHP resulted in higher patient satisfaction than EH and MP [102]. Again, laser treatment might represent an attractive future treatment option. Its efficacy needs to be tested with further prospective trials.

\section{CONCLUSION}

Anal cushions are normal structures contributing to continence, but may become abnormal resulting in symptomatic haemorrhoids following straining and other factors. Many patients with haemorrhoids simply seek reassurance that they do not have more serious pathology, and do not require any specific treatment. First- and second-degree haemorrhoids often respond to conservative and nonsurgical measures. Larger prolapsing haemorrhoids require surgery. Conventional haemorrhoidectomy remains an important part of haemorrhoid management, and offers favourable long-term cure rates; however, it is associated with consideration pain and occasional severe complications. Newer techniques promise to be less painful, yet long-term results are uncertain and questions remain regarding their recurrence rates. A patient with symptomatic haemorrhoids should be counselled regarding the advantages and disadvantages of each surgical approach, and surgeons managing haemorrhoids should be skilled in a variety of techniques to offer a tailored management strategy for each patient.

\section{CONFLICT OF INTEREST}

No potential conflict of interest relevant to this article was reported.

\section{ACKNOWLEDGMENTS}

Dr. Kheng-Seong Ng is supported by the Mitchell J. Notaras Fellowship in Colorectal Surgery. The authors thank all patients whose deidentified photographs are presented as figures in this paper. Consent was obtained preoperatively from all patients for their photographs to be used for educational and research purposes, such as in this paper.

\section{REFERENCES}

1. Parks AG. De haemorrhois: a study in surgical history. Guys Hosp Rep 1955;104:135-56.

2. Thomson WH. The nature and cause of haemorrhoids. Proc $\mathrm{R}$ Soc Med 1975;68:574-5.

3. Margetis N. Pathophysiology of internal hemorrhoids. Ann Gastroenterol 2019;32:264-72.

4. Thomson WH. The nature of haemorrhoids. Br J Surg 1975;62: 542-52.

5. Lestar B, Penninckx F, Kerremans R. The composition of anal basal pressure. An in vivo and in vitro study in man. Int J Colorectal Dis 1989;4:118-22.

6. Lorenzo-Rivero S. Hemorrhoids: diagnosis and current manage- 
ment. Am Surg 2009;75:635-42.

7. Lohsiriwat V. Hemorrhoids: from basic pathophysiology to clinical management. World J Gastroenterol 2012;18:2009-17.

8. Singer AJ, Brandt LJ. Pathophysiology of the gastrointestinal tract during pregnancy. Am J Gastroenterol 1991;86:1695-712.

9. Dehn TC, Kettlewell MG. Haemorrhoids and defaecatory habits. Lancet 1989;1:54-5.

10. Sandler RS, Peery AF. Rethinking what we know about hemorrhoids. Clin Gastroenterol Hepatol 2019;17:8-15.

11. Jacobs D. Clinical practice. Hemorrhoids. N Engl J Med 2014; 371:944-51.

12. Rubbini M, Ascanelli S. Classification and guidelines of hemorrhoidal disease: present and future. World J Gastrointest Surg 2019;11:117-21.

13. Lunniss PJ, Mann CV. Classification of internal haemorrhoids: a discussion paper. Colorectal Dis 2004;6:226-32.

14. Sun Z, Migaly J. Review of hemorrhoid disease: presentation and management. Clin Colon Rectal Surg 2016;29:22-9.

15. Hardy A, Chan CL, Cohen CR. The surgical management of haemorrhoids-a review. Dig Surg 2005;22:26-33.

16. Hardy A, Cohen CR. The acute management of haemorrhoids. Ann R Coll Surg Engl 2014;96:508-11.

17. Idrees JJ, Clapp M, Brady JT, Stein SL, Reynolds HL, Steinhagen E. Evaluating the accuracy of hemorrhoids: comparison among specialties and symptoms. Dis Colon Rectum 2019;62:867-71.

18. Gearhart SL. Symptomatic hemorrhoids. Adv Surg 2004;38:16782.

19. Hollingshead JR, Phillips RK. Haemorrhoids: modern diagnosis and treatment. Postgrad Med J 2016;92:4-8.

20. Alonso-Coello P, Mills E, Heels-Ansdell D, Lopez-Yarto M, Zhou Q, Johanson JF, et al. Fiber for the treatment of hemorrhoids complications: a systematic review and meta-analysis. Am J Gastroenterol 2006;101:181-8.

21. Acheson AG, Scholefield JH. Management of haemorrhoids. BMJ 2008;336:380-3.

22. Altomare DF, Giannini I. Pharmacological treatment of hemorrhoids: a narrative review. Expert Opin Pharmacother 2013;14: 2343-9.

23. Johanson JF. Nonsurgical treatment of hemorrhoids. J Gastrointest Surg 2002;6:290-4.

24. van Tol RR, Bruijnen MPA, Melenhorst J, van Kuijk SMJ, Stassen LPS, Breukink SO. A national evaluation of the management practices of hemorrhoidal disease in the Netherlands. Int J Colorectal Dis 2018;33:577-88.

25. Brown SR. Haemorrhoids: an update on management. Ther Adv Chronic Dis 2017;8:141-7.

26. Sajid MS, Bhatti MI, Caswell J, Sains P, Baig MK. Local anaesthetic infiltration for the rubber band ligation of early symptomatic haemorrhoids: a systematic review and meta-analysis. Updates Surg 2015;67:3-9.

27. Albuquerque A. Rubber band ligation of hemorrhoids: a guide for complications. World J Gastrointest Surg 2016;8:614-20.
28. Johanson JF, Rimm A. Optimal nonsurgical treatment of hemorrhoids: a comparative analysis of infrared coagulation, rubber band ligation, and injection sclerotherapy. Am J Gastroenterol 1992;87:1600-6.

29. Cocorullo G, Tutino R, Falco N, Licari L, Orlando G, Fontana T, et al. The non-surgical management for hemorrhoidal disease. A systematic review. G Chir 2017;38:5-14.

30. Thomson WH. Banding and injection of piles. Ann R Coll Surg Engl 2001;83:361-2.

31. Senapati A, Nicholls RJ. A randomised trial to compare the results of injection sclerotherapy with a bulk laxative alone in the treatment of bleeding haemorrhoids. Int J Colorectal Dis 1988; 3:124-6.

32. Santos G, Novell JR, Khoury G, Winslet MC, Lewis AA. Longterm results of large-dose, single-session phenol injection sclerotherapy for hemorrhoids. Dis Colon Rectum 1993;36:958-61.

33. Seow-Choen F, Ho YH, Ang HG, Goh HS. Prospective, randomized trial comparing pain and clinical function after conventional scissors excision/ligation vs. diathermy excision without ligation for symptomatic prolapsed hemorrhoids. Dis Colon Rectum 1992;35:1165-9.

34. Mushaya CD, Caleo PJ, Bartlett L, Buettner PG, Ho YH. Harmonic scalpel compared with conventional excisional haemorrhoidectomy: a meta-analysis of randomized controlled trials. Tech Coloproctol 2014;18:1009-16.

35. Fleshman J. Advanced technology in the management of hemorrhoids: stapling, laser, harmonic scalpel, and ligasure. J Gastrointest Surg 2002;6:299-301.

36. Filingeri V, Gravante G, Baldessari E, Grimaldi M, Casciani CU. Prospective randomized trial of submucosal hemorrhoidectomy with radiofrequency bistoury vs. conventional Parks' operation. Tech Coloproctol 2004;8:31-6.

37. Moult HP, Aubert M, De Parades V. Classical treatment of hemorrhoids. J Visc Surg 2015;152(2 Suppl):S3-9.

38. Shanmugam V, Thaha MA, Rabindranath KS, Campbell KL, Steele RJ, Loudon MA. Systematic review of randomized trials comparing rubber band ligation with excisional haemorrhoidectomy. Br J Surg 2005;92:1481-7.

39. Johannsson HO, Graf W, Pahlman L. Long-term results of haemorrhoidectomy. Eur J Surg 2002;168:485-9.

40. Rakinic J, Poola VP. Hemorrhoids and fistulas: new solutions to old problems. Curr Probl Surg 2014;51:98-137.

41. Johannsson HO, Pahlman L, Graf W. Randomized clinical trial of the effects on anal function of Milligan-Morgan versus Ferguson haemorrhoidectomy. Br J Surg 2006;93:1208-14.

42. Ho YH, Buettner PG. Open compared with closed haemorrhoidectomy: meta-analysis of randomized controlled trials. Tech Coloproctol 2007;11:135-43.

43. Bhatti MI, Sajid MS, Baig MK. Milligan-Morgan (Open) versus ferguson haemorrhoidectomy (Closed): a systematic review and meta-analysis of published randomized, controlled trials. World J Surg 2016;40:1509-19. 
44. Nienhuijs S, de Hingh I. Conventional versus LigaSure hemorrhoidectomy for patients with symptomatic Hemorrhoids. Cochrane Database Syst Rev 2009;2009:CD006761.

45. Xu L, Chen H, Lin G, Ge Q. Ligasure versus Ferguson hemorrhoidectomy in the treatment of hemorrhoids: a meta-analysis of randomized control trials. Surg Laparosc Endosc Percutan Tech 2015;25:106-10.

46. Sammour T, Barazanchi AW, Hill AG, group P. Evidence-based management of pain after excisional haemorrhoidectomy surgery: a PROSPECT review update. World J Surg 2017;41:603-14.

47. Joshi GP, Neugebauer EA, Collaboration P. Evidence-based management of pain after haemorrhoidectomy surgery. Br J Surg 2010;97:1155-68.

48. Misra MC, Imlitemsu. Drug treatment of haemorrhoids. Drugs 2005;65:1481-91.

49. Ratnasingham K, Uzzaman M, Andreani SM, Light D, Patel B. Meta-analysis of the use of glyceryl trinitrate ointment after haemorrhoidectomy as an analgesic and in promoting wound healing. Int J Surg 2010;8:606-11.

50. Liu JW, Lin CC, Kiu KT, Wang CY, Tam KW. Effect of glyceryl trinitrate ointment on pain control after hemorrhoidectomy: a meta-analysis of randomized controlled trials. World J Surg 2016;40:215-24.

51. Yadav S, Khandelwal RG, Om P, Ravindra K, Choudhary KL. A prospective randomized double-blind study of pain control by topical calcium channel blockers versus placebo after MilliganMorgan hemorrhoidectomy. Int J Colorectal Dis 2018;33:895-9.

52. Rodriguez-Wong U, Ocharan-Hernandez ME, Toscano-Garibay J. Topical diltiazem for pain after closed hemorrhoidectomy. Rev Gastroenterol Mex 2016;81:74-9.

53. Siddiqui MR, Abraham-Igwe C, Shangumanandan A, Grassi V, Swift I, Abulafi AM. A literature review on the role of chemical sphincterotomy after Milligan-Morgan hemorrhoidectomy. Int J Colorectal Dis 2011;26:685-92.

54. Ala S, Alvandipour M, Saeedi M, Mansourifar M, Monajati M, Shiva A. Effect of topical baclofen $5 \%$ on post-hemorrhoidectomy pain: randomized double blind placebo-controlled clinical trial. J Gastrointest Surg 2020;24:405-10.

55. Ala S, Saeedi M, Eshghi F, Mirzabeygi P. Topical metronidazole can reduce pain after surgery and pain on defecation in postoperative hemorrhoidectomy. Dis Colon Rectum 2008;51:235-8.

56. Nicholson TJ, Armstrong D. Topical metronidazole (10 percent) decreases posthemorrhoidectomy pain and improves healing. Dis Colon Rectum 2004;47:711-6.

57. Balfour L, Stojkovic SG, Botterill ID, Burke DA, Finan PJ, Sagar PM. A randomized, double-blind trial of the effect of metronidazole on pain after closed hemorrhoidectomy. Dis Colon Rectum 2002;45:1186-90.

58. Wanis KN, Emmerton-Coughlin HM, Coughlin S, Foley N, Vinden C. Systemic metronidazole may not reduce posthemorrhoidectomy pain: a meta-analysis of randomized controlled trials. Dis Colon Rectum 2017;60:446-55.
59. Xia W, Manning JPR, Barazanchi AWH, Su’a B, Hill AG. Metronidazole following excisional haemorrhoidectomy: a systematic review and meta-analysis. ANZ J Surg 2018;88:408-14.

60. Lyons NJR, Cornille JB, Pathak S, Charters P, Daniels IR, Smart NJ. Systematic review and meta-analysis of the role of metronidazole in post-haemorrhoidectomy pain relief. Colorectal Dis 2017;19:803-11.

61. Nyam DC, Seow-Choen F, Ho YH. Submucosal adrenaline injection for posthemorrhoidectomy hemorrhage. Dis Colon Rectum 1995;38:776-7.

62. Lee KC, Liu CC, Hu WH, Lu CC, Lin SE, Chen HH. Risk of delayed bleeding after hemorrhoidectomy. Int J Colorectal Dis 2019;34:247-53.

63. Zaheer S, Reilly WT, Pemberton JH, Ilstrup D. Urinary retention after operations for benign anorectal diseases. Dis Colon Rectum 1998;41:696-704.

64. McCloud JM, Jameson JS, Scott AN. Life-threatening sepsis following treatment for haemorrhoids: a systematic review. Colorectal Dis 2006;8:748-55.

65. Eu KW, Teoh TA, Seow-Choen F, Goh HS. Anal stricture following haemorrhoidectomy: early diagnosis and treatment. Aust N Z J Surg 1995;65:101-3.

66. Ommer A, Wenger FA, Rolfs T, Walz MK. Continence disorders after anal surgery-a relevant problem? Int J Colorectal Dis 2008; 23:1023-31.

67. Stamatiadis A, Konstantinou E, Theodosopoulou E, Mamoura K. Frequency of operative trauma to anal sphincters: evaluation with endoanal ultrasound. Gastroenterol Nurs 2002;25:55-9.

68. Jayne DG, Seow-Choen F. Modified stapled haemorrhoidopexy for the treatment of massive circumferentially prolapsing piles. Tech Coloproctol 2002;6:191-3.

69. Nystrom PO, Qvist N, Raahave D, Lindsey I, Mortensen N, Stapled or open pile procedure trial study g. Randomized clinical trial of symptom control after stapled anopexy or diathermy excision for haemorrhoid prolapse. Br J Surg 2010;97:167-76.

70. Thaha MA, Campbell KL, Kazmi SA, Irvine LA, Khalil A, Binnie $\mathrm{NR}$, et al. Prospective randomised multi-centre trial comparing the clinical efficacy, safety and patient acceptability of circular stapled anopexy with closed diathermy haemorrhoidectomy. Gut 2009;58:668-78.

71. Tjandra JJ, Chan MK. Systematic review on the procedure for prolapse and hemorrhoids (stapled hemorrhoidopexy). Dis Colon Rectum 2007;50:878-92.

72. Watson AJ, Cook J, Hudson J, Kilonzo M, Wood J, Bruhn H, et al. A pragmatic multicentre randomised controlled trial comparing stapled haemorrhoidopexy with traditional excisional surgery for haemorrhoidal disease: the eTHoS study. Health Technol Assess 2017;21:1-224.

73. Jayaraman S, Colquhoun PH, Malthaner RA. Stapled hemorrhoidopexy is associated with a higher long-term recurrence rate of internal hemorrhoids compared with conventional excisional hemorrhoid surgery. Dis Colon Rectum 2007;50:1297-305. 
74. Shao WJ, Li GC, Zhang ZH, Yang BL, Sun GD, Chen YQ. Systematic review and meta-analysis of randomized controlled trials comparing stapled haemorrhoidopexy with conventional haemorrhoidectomy. Br J Surg 2008;95:147-60.

75. Ortiz H, Marzo J, Armendariz P, De Miguel M. Stapled hemorrhoidopexy vs. diathermy excision for fourth-degree hemorrhoids: a randomized, clinical trial and review of the literature. Dis Colon Rectum 2005;48:809-15.

76. Pescatori M, Gagliardi G. Postoperative complications after procedure for prolapsed hemorrhoids (PPH) and stapled transanal rectal resection (STARR) procedures. Tech Coloproctol 2008;12: 7-19.

77. van Wensen RJ, van Leuken MH, Bosscha K. Pelvic sepsis after stapled hemorrhoidopexy. World J Gastroenterol 2008;14:59246.

78. Guy RJ, Seow-Choen F. Septic complications after treatment of haemorrhoids. Br J Surg 2003;90:147-56.

79. Sturiale A, Fabiani B, Menconi C, Cafaro D, Fusco F, Bellio G, et al. Long-term results after stapled hemorrhoidopexy: a survey study with mean follow-up of 12 years. Tech Coloproctol 2018; 22:689-96.

80. Giordano P, Overton J, Madeddu F, Zaman S, Gravante G. Transanal hemorrhoidal dearterialization: a systematic review. Dis Colon Rectum 2009;52:1665-71.

81. Ratto C. THD Doppler procedure for hemorrhoids: the surgical technique. Tech Coloproctol 2014;18:291-8.

82. Figueiredo MN, Campos FG. Doppler-guided hemorrhoidal dearterialization/transanal hemorrhoidal dearterialization: Technical evolution and outcomes after 20 years. World J Gastrointest Surg 2016;8:232-7.

83. Giamundo P. Advantages and limits of hemorrhoidal dearterialization in the treatment of symptomatic hemorrhoids. World J Gastrointest Surg 2016;8:1-4.

84. Vinson-Bonnet B, Higuero T, Faucheron JL, Senejoux A, Pigot F, Siproudhis L. Ambulatory haemorrhoidal surgery: systematic literature review and qualitative analysis. Int J Colorectal Dis 2015;30:437-45.

85. Trenti L, Biondo S, Kreisler Moreno E, Sanchez-Garcia JL, EspinBasany E, Landaluce-Olavarria A, et al. Short-term outcomes of transanal hemorrhoidal dearterialization with mucopexy versus vessel-sealing device hemorrhoidectomy for grade III to IV hemorrhoids: a prospective randomized multicenter trial. Dis Colon Rectum 2019;62:988-96.

86. Popov V, Yonkov A, Arabadzhieva E, Zhivkov E, Bonev S, Bulanov D, et al. Doppler-guided transanal hemorrhoidal dearterilization versus conventional hemorrhoidectomy for treatment of hemorrhoids - early and long-term postoperative results. BMC Surg 2019;19:4.

87. Atallah S, Maharaja GK, Martin-Perez B, Burke JP, Albert MR, Larach SW. Transanal hemorrhoidal dearterialization (THD): a safe procedure for the anticoagulated patient? Tech Coloproctol 2016;20:461-6.
88. Brown SR, Tiernan JP, Watson AJM, Biggs K, Shephard N, Wailoo AJ, et al. Haemorrhoidal artery ligation versus rubber band ligation for the management of symptomatic second-degree and third-degree haemorrhoids (HubBLe): a multicentre, open-label, randomised controlled trial. Lancet 2016;388:356-64.

89. Bach SP, Fearnhead NS. Does HubBLe spell trouble for HAL? Lancet 2016;388:311-2.

90. Altomare DF, Giuratrabocchetta S. Conservative and surgical treatment of haemorrhoids. Nat Rev Gastroenterol Hepatol 2013;10:513-21.

91. Sultan S. Longo procedure (Stapled hemorrhoidopexy): Indications, results. J Visc Surg 2015;152(2 Suppl):S11-4.

92. Faucheron JL, Poncet G, Voirin D, Badic B, Gangner Y. Dopplerguided hemorrhoidal artery ligation and rectoanal repair (HALRAR) for the treatment of grade IV hemorrhoids: long-term results in 100 consecutive patients. Dis Colon Rectum 2011;54: 226-31.

93. Eu KW, Seow-Choen F, Goh HS. Comparison of emergency and elective haemorrhoidectomy. Br J Surg 1994;81:308-10.

94. Grace RH, Creed A. Prolasping thrombosed haemorrhoids: outcome of conservative management. Br Med J 1975;3:354.

95. Zuber TJ. Hemorrhoidectomy for thrombosed external hemorrhoids. Am Fam Physician 2002;65:1629-32, 1635-6, 1639.

96. Eddama MMR, Everson M, Renshaw S, Taj T, Boulton R, Crosbie J, et al. Radiofrequency ablation for the treatment of haemorrhoidal disease: a minimally invasive and effective treatment modality. Tech Coloproctol 2019;23:769-74.

97. Gupta PJ, Heda PS, Kalaskar S. Radiofrequency ablation and plicationa new technique for prolapsing hemorrhoidal disease. Curr Surg 2006;63:44-50.

98. Filingeri V, Angelico R, Bellini MI, Manuelli M, Sforza D. Prospective randomised comparison of rubber band ligation (RBL) and combined hemorrhoidal radiocoagulation (CHR). Eur Rev Med Pharmacol Sci 2012;16:224-9.

99. Naderan M, Shoar S, Nazari M, Elsayed A, Mahmoodzadeh H, Khorgami Z. A randomized controlled trial comparing laser intra-hemorrhoidal coagulation and Milligan-Morgan hemorrhoidectomy. J Invest Surg 2017;30:325-31.

100. Giamundo P, Cecchetti W, Esercizio L, Fantino G, Geraci M, Lombezzi R, et al. Doppler-guided hemorrhoidal laser procedure for the treatment of symptomatic hemorrhoids: experimental background and short-term clinical results of a new mini-invasive treatment. Surg Endosc 2011;25:1369-75.

101. De Nardi P, Tamburini AM, Gazzetta PG, Lemma M, Pascariello A, Asteria CR. Hemorrhoid laser procedure for second- and third-degree hemorrhoids: results from a multicenter prospective study. Tech Coloproctol 2016;20:455-9.

102. Poskus T, Danys D, Makunaite G, Mainelis A, Mikalauskas S, Poskus E, et al. Results of the double-blind randomized controlled trial comparing laser hemorrhoidoplasty with sutured mucopexy and excisional hemorrhoidectomy. Int J Colorectal Dis 2020;35:481-90. 